\title{
La conquista de Asturias por Roma: una nueva perspectiva
}

\author{
Narciso SANTOS YANGUAS \\ Universidad de Oviedo \\ nsantos@uniovi.es
}

\section{RESUMEN}

La documentación antigua no permite concretar la presencia de militares romanos en Asturias durante las guerras astur-cántabras; y algo similar sucede con respecto a los restos materiales. Por ello creemos que las acciones militares se llevarían a cabo en la línea de la cordillera cantábrica (en territorio de los astures cismontanos) y en la franja litoral (con participación de la escuadra romana del Cantábrico). La zona interior del suelo asturiano sería controlada con posterioridad a través de vías de comunicación cuyo trazado se diseñaría a la finalización de los combates y se consolidaría con los sucesores de Augusto.

Palabras clave: Presencia militar romana. Guerras astur-cántabras. Cordillera Cantábrica. Franja litoral. Vías de comunicación. Augusto. Sucesores.

\section{The Roman Conquest of Asturias: A New approach}

\begin{abstract}
The ancient evidence does not clarify the Roman military presence in Asturias during the period of the Asturian-Cantabrian wars. Somenthing similar happens to the archaeological remains.

Therefore we think the military actions could be developed in the Cantabrian mountain range (into the territory of the Asturian people) and in the littoral strip (the participation of the Roman fleet). The hinterland could have been controlled afterwards through communication routes. The design of these routes was done after the end of the wars and was consolidated in times of Augustus' successors.
\end{abstract}

Key Words: Roman military presence. Asturian-Cantabrian Wars. Cantabrian Mountain. Littoral strip. Communication routes. Augustus. Succesors. 
La anexión del territorio habitado por las poblaciones septentrionales hispanas durante las guerras astur-cántabras se halla en la base de su integración en los parámetros de vida romanos; este proceso de conquista, dirigido y encabezado por el propio Augusto, solo se comprende en el marco general de la política militar del Estado romano, cuyos objetivos se centraban en la implantación sobre la Península Ibérica (y el Occidente europeo en general) de una organización administrativa estable y uniforme. ${ }^{1}$

Tras el restablecimiento del poder político en Roma, una vez superados los avatares de la guerra civil e inaugurada la nueva forma de gobierno por Augusto, los habitantes del cuadrante noroccidental hispano pasarían a ser considerados, por decreto, enemigos del Imperio, convirtiéndose en necesaria su subyugación inmediata de acuerdo con las directrices políticas del Estado. Debido a ello el primer emperador llevaría a cabo en persona la dirección de las campañas militares contra cántabros, astures y galaicos, aunque las operaciones bélicas se ejecutarían, sobre todo, bajo la dirección de sus legados (gobernadores provinciales). ${ }^{2}$ No vamos a analizar aquí los motivos y objetivos que impulsarían a los romanos a dicha anexión, desde la salvaguarda de las fronteras con el territorio ya pacificado (Floro, Compendio de historia romana $2.33 .46-47$ ), ${ }^{3}$ pasando por otros de índole económica, centrados a medio plazo en el aprovechamiento de los recursos mineros, en especial el oro y la plata, pero también el estaño desde la época de Publio Craso y Julio César. ${ }^{4}$

Esta causa económica no constituiría el móvil principal, pues el primer emperador tendría presente igualmente en su planteamiento inicial la reorganización administrativa del Occidente mediterráneo y la expansión y arraigo de una cultura itálica frente a las corrientes orientalizantes del momento, además de resolver a un mismo tiempo cuestiones de política exterior y carácter militar con el fin de establecer unas fronteras que hicieran posible la vida en paz del ciudadano romano. ${ }^{5}$ De cualquier forma la anexión del suelo habitado por las poblaciones castreñas de la cornisa cantábrica, así como su integración en el marco administrativo romano, implicarían todo un conjunto de singularidades, que vamos a tratar de analizar a continuación.

Hemos de destacar, en primer lugar, el hecho de que las circunstancias y las diferentes fases de desarrollo de la anexión de dicho territorio por parte de Roma no aparecen recogidas más que de forma muy parcial en la documentación escrita antigua (Floro, Orosio, Dión Casio...) y que, en cualquier caso, no nos permiten una reconstrucción pormenorizada y completa de los acontecimientos. Además, si esa dificultad sobresale con respecto a los enfrentamientos militares que tendrían como marco geográfico el suelo de los astures augustanos de León y el Norte de Zamora, la situación se acentúa en el caso de los transmontanos de Asturias y las poblaciones de la cornisa cantábrica al no disponer de ninguna referencia en las fuentes escritas sobre dicho problema y contar únicamente con algunos restos materiales que, siempre de manera indirecta, nos

\footnotetext{
1 Martino 1987 y 1989.

2 SANTOS 1982.

3 SANTOS 1988, 25-28.

4 Estrabón, Geografia 3.5.11.

5 SANTOS 2014a, 202-203.
} 
pueden ayudar a comprender el fenómeno de la anexión de dicho territorio en época de Augusto. ${ }^{6}$

Sin embargo, la administración romana incidiría directamente sobre la forma de vida de sus habitantes, tanto desde el punto de vista económico como social; en este sentido la integración paulatina de los astures en la organización romana se llevaría a efecto en fases sucesivas: por un lado a través de su participación en el ejército (generalmente como tropas auxiliares) ${ }^{7} \mathrm{y}$, a continuación, como mano de obra no especializada en las minas de oro explotadas por los romanos en los distritos mineros del NO peninsular. ${ }^{8}$ En la descripción de los principales avatares de las guerras astur-cántabras apenas se constata, de forma muy somera, la presencia de cántabros, astures (transmontanos) y galaicos que ocupaban el suelo correspondiente al actual Principado de Asturias en sus diferentes regiones, lo que nos permite reconsiderar las peculiaridades que encierra la conquista romana de dicho marco geográfico. Ante todo hemos de tener en cuenta que la política de anexión territorial conllevaba unos objetivos prácticos evidentes, de manera que los romanos difícilmente se adentraban en aquellos territorios en los que el aprovechamiento de los recursos económicos de dicho suelo en los años posteriores no compensara los esfuerzos militares realizados con anterioridad. ${ }^{9}$

Tal vez sea esto lo que pueda explicar el hecho de que, en la región norteña de la cordillera cantábrica (entre dicho relieve montañoso y el mar) los restos de presencia militar romana de carácter relevante sean muy escasos (al menos hasta la actualidad), ${ }^{10}$ añadiéndose además el hecho de que ni la toponimia relacionada con ello ni su singularidad (ladrillo cerámico de Gijón, águila legionaria de la zona de Cangas del Narcea, lápidas de soldados -todas ellas posteriores-, topónimos derivados de términos latinos de carácter militar...) se pueden fechar en las últimas décadas del siglo I antes de nuestra era, coincidiendo con los primeros años de presencia romana en Asturias. En ese ámbito de confusión derivado de las características de las fuentes antiguas con respecto al desarrollo de los principales acontecimientos de las guerras astur-cántabras es posible que el único referente al territorio de Asturias, si las identificaciones geográfica y toponímica son correctas, haya que relacionarlo con el ataque al mons Vindius, episodio militar que ha suscitado algunos problemas de localización, ${ }^{11}$ haciéndolo coincidir con el puerto Ventana en la cordillera cantábrica. Se plantea la posibilidad de relacionar dicho orónimo con una divinidad indígena fuertemente vinculada a la divinización de los fenómenos naturales, el dios Vindonnus, Vindonus o Vindonius, que para algunos investigadores puede encontrarse en la base del actual topónimo Bendueños, en el concejo asturiano de Lena: se trataría del dios blanco (en correspondencia el mons Vindius

6 En otros términos: la conquista del suelo de la actual Asturias por Roma constituye una singularidad en el marco de los enfrentamientos militares dirigidos por Augusto en el Norte peninsular dado que ningún documento (ni escrito ni arqueológico) nos pone en contacto con ella.

7 Más detalles en SANTOS 2010b.

8 Mangas 1996, 50-53.

9 SANTOS 2006a, 39-41.

10 Pues no pueden considerarse como tales por su cronología más tardía los reducidos enclaves campamentales que van apareciendo en torno a las explotaciones mineras más representativas (ver, por ejemplo, GonzÁlez - MEnÉndez - Álvarez 2008 para el distrito aurífero romano de Bustantigo).

11 Ver, por ejemplo PASTOR 1977. 
como monte blanco sería el lugar de su epifanía), quizás equiparable al Apolo romano, al que recurrirían los astures en el momento en que la presencia del ejército romano pudo hacerse efectiva. ${ }^{12}$

Por otro lado no podemos obviar que una parte de dichos entornos geográficos quedaría en manos de los antiguos jefes de las comunidades indígenas castreñas, quienes, tal vez como premio a la causa romana, controlarían directamente estos territorios con el beneplácito de Roma y mediante la transformación de las funciones administrativas que desempeñaban en el seno de sus antiguos poblados en las nuevas romanas. Nos hallamos así ante casos tan explícitos y significativos como el del princeps Cantabrorum de la región montañosa de los cántabros antiguos, cuyo control se ejercería sobre un buen número de los pasos de la cordillera entre León y Cantabria, ${ }^{13} \mathrm{o}$ el del princeps Albionum, en la zona galaica del occidente de Asturias..$^{14}$ Únicamente disponemos de indicios de posibles enfrentamientos bélicos entre astures y romanos en el límite del suelo que separaba a los astures transmontanos de los augustanos entre las actuales provincias de León y Asturias (sierra de Curriechos, en el cordal de La Carisa), aunque no podamos afirmar, de acuerdo con los restos materiales con que contamos en la actualidad (una moneda que se fecha en torno al año 90 a.C., restos del instrumental propio de los destacamentos militares romanos...) que en dicho enclave se desarrollara la gran batalla de los astures contra los romanos ni que allí se produjera el asentamiento de unidad legionaria romana alguna, ${ }^{15}$ entre otras cosas porque el entorno geográfico no haría posible la supervivencia, ni siquiera temporal, de ningún campamento estable. Si añadimos a ello, además, el hecho de que la escuadra romana del Cantábrico (classis Cantabrica) contribuiría igualmente al sometimiento de las poblaciones septentrionales, como parecen documentarnos perfectamente las Aras Sestianas de la Campa Torres, ${ }^{16}$ es posible recomponer, aunque sea a grandes rasgos, los avatares históricos por los que atravesarían los astures transmontanos a la llegada de Roma. Quizás, como sucedería igualmente con respecto a Cantabria y Galicia, a pesar de que en estas dos regiones posiblemente de forma menos pronunciada (en especial en la segunda), el control romano del territorio se llevaría a cabo tomando como referentes dos áreas estratégicas, una terrestre y otra marítima, es decir desde la zona de cumbres de la cordillera cantábrica y desde la línea marítima: ${ }^{17}$ ello supondría que solamente la franja costera (en torno a unos 25-30 kms en línea recta desde el litoral) se encontraría bajo la supervisión directa de Roma, mientras que el resto de los astures transmontanos camparían libremente por su suelo.

De esta manera el control del territorio correspondiente a la Asturias antigua se concretaría (y en ocasiones más virtual que prácticamente) desde los campamentos romanos establecidos entre los astures augustanos, a pesar de que ello no supondría en ningún momento que los soldados que los ocupaban contarían entre sus objetivos con la

12 Santos 2014c.

13 MANGaS - Martino 1997, 321ss.

14 SANTOS 2002. Ver igualmente SANTOS 2014b.

15 Y menos todavía asignarle nombre, como se ha cometido la imprudencia de hacer a veces un poco a la ligera y sin ninguna referencia documental (la legión V Alauda, que no Alaudae).

16 Más detalles en Maya - Cuesta 2001. Cf. Peralta 2004.

17 CABrero 2011. 
supervisión absoluta de todo el espacio correspondiente a la Asturias actual. ${ }^{18}$ Teniendo como referentes esos mismos campamentos las tropas romanas supervisarían las vías de penetración hacia el suelo de los astures transmontanos, siendo ese camino hacia el litoral cantábrico (vía de La Carisa) el que nos presentará (algunas décadas después) los restos más significativos de la presencia romana en la región. Como consecuencia de ello en los siglos posteriores no sólo vamos a encontrar en los aledaños de dicho trazado algunos de los documentos epigráficos más importantes al respecto (consagración a Júpiter hallada en la iglesia de Serrapio - concejo de Aller-, ${ }^{19}$ villa de Memoriana -Lena-, inscripciones de Ujo -Mieres- ${ }^{20}$ sino también algunos de los topónimos de posible raíz militar, como Priorio (más que probable derivación de praetorium), Tudela (equivalente al término latino tutela) hasta alcanzar la costa (polis Noega y Gigia), donde, coincidiendo con sus orígenes, parece detectarse la presencia de un destacamento de la legión IIII Macedónica. ${ }^{21}$

Junto a ello los testimonios de la etapa romana posterior nos conducen a una realidad similar, consistente en que la mayor preocupación de la administración romana se centraría en controlar y llevar a cabo el aprovechamiento del Occidente asturiano, rico en recursos auríferos (y en consecuencia la presencia en dicha región se convertiría en más continuada y profunda), combinando su explotación con los distritos mineros existentes en la región de El Bierzo leonés. Por otro lado, desde el punto de vista de la documentación epigráfica, observamos que la mayoría de las inscripciones de Asturias se conecta con esa franja costera que hemos mencionado más arriba, donde los contactos comerciales y de todo tipo serían más intensos, así como con las vías de comunicación que ponían en conexión la región meridional con la septentrional de la cordillera cantábrica.

En este sentido, además del camino que conducía a Gijón, ${ }^{22}$ sobresale el que ponía en contacto Lucus Asturum (Lugo de Llanera) con Lucus Augusti (Lugo de Galicia), ${ }^{23}$ cuyo trazado, frente a lo que pensaba J. M. González, ${ }^{24}$ creemos que discurriría por el interior y no por el litoral. Así, en el territorio próximo al Gijón romano, tal vez aprovechando la ría del Aboño (vinculada al poblado de la Campa Torres, asentamiento de las Aras Sestianas), o en el emplazamiento más antiguo de la actual ciudad gijonesa, donde un reducido destacamento militar (posiblemente de la legión IIII Macedónica) se hallaría en el origen del núcleo urbano posterior en la península de Cimadevilla, ${ }^{25}$ recalarían algunos barcos de esta escuadra romana del Cantábrico; su objetivo se centraría en el abastecimiento de los productos agropecuarios generados como excedente por las abundantes villae enclavadas en su entorno territorial ya desde finales del siglo I d.C. Y en este contexto hemos de referirnos igualmente a una importante vía de comunicación de tiempos romanos, que uniría los centros de población de Lucus Asturum y Gigia,

\footnotetext{
18 Así se explicaría que ninguno de los recintos castreños del Principado denote un nivel de cenizas en su estratigrafía, como correspondería a su arrasamiento por los ejércitos romanos.

19 CIL II, 2697. Cf. SAntos 2013b.

20 Burgos 2007, 103-118.

21 Para más detalles remitimos, entre otros, a GonZÁlez ECHEGARAY - SOlANA 1975.

22 ÁlvareZ MARRERO 1985.

23 GONZÁLEZ - CARREÑO 1998.

24 GonZÁLEZ 1956, 287-289.

25 Para más detalles ver, entre otros, SANTOS 1996, 222-223.
} 
poniendo en contacto así el centro viario más importante de Asturias y la ciudad asturromana más representativa del litoral astur: al parecer este trazado caminero de Lucus Asturum a Gijón no constituiría más que el enlace final de una vía que el Anónimo de Rávena hace arrancar de Legio VII (León), de modo que, tras ascender por el cauce del Bernesga, pasaría por Interamnium (límite entre León y Asturias), penetraría en suelo asturiano por el camino real de La Carisa, bajaría hasta Memoriana (Lena), atravesaría junto al enclave de Ujo (concejo de Mieres) y alcanzaría con posterioridad el centro urbano de Lucus. ${ }^{26}$

En Ujo se ha descubierto un grupo de inscripciones que puede interpretarse como indicador del proceso de romanización que tendría lugar en el entorno territorial de dicho enclave; destacan dos de carácter militar: la primera se halla vinculada a la presencia del único personaje del territorio asturiano que desempeñaría, entre otros cargos (prefecto de los symmachiarios astures), la comandancia del campamento de la legión III Augusta, asentada en Lambaesis (provincia romana de Numidia). ${ }^{27}$ Sin embargo, el documento más significativo lo constituye tal vez la estela dedicada a Júpiter por un soldado de la legión VII Gemina (junto a su mujer), que puede constituir un exponente, no solo de la romanización de dicho territorio a través de la vía de comunicación que estamos analizando, sino también de la adopción de las formas religiosas romanas como expresión política de la nueva realidad social (CIL II, 5733).

Por su parte la inscripción votiva de Lugo de Llanera a los Lares Viales parece confirmar la importancia de dicho enclave como centro viario y nudo de comunicaciones; ${ }^{28}$ sin duda esta ruta romana adquiriría una importancia similar a la que desde Asturica Augusta (Astorga) ascendería por el cauce del Tuerto (o bien por el valle del Órbigo) hasta alcanzar el puerto de La Mesa, bajando por la zona alta de los cordales hasta desembocar en el centro astur-romano de Flavionavia (Santianes de Pravia en la desembocadura del Nalón). ${ }^{29}$ El recorrido del trazado desde Lucus Asturum se alargaría hasta el emplazamiento de Gigia tras atravesar el río Noreña y los enclaves de Tejera, Los Llanos, zona de Veranes, Beloño, Cenero, Sotiello, La Muria, Picota, Tremañes y Braña antes de alcanzar la península de Cimadevilla y el cerro de Santa Catalina; poco después de Cenero, y antes de alcanzar Sotiello, un ramal desembocaba en la Campa Torres, contando en la actualidad en el ámbito del casco urbano gijonés con el topónimo La Calzada, recuerdo imborrable del trazado antiguo. ${ }^{30}$ Por su parte en el trazado de la ruta romana de Lucus Asturum a Lucus Augusti halla explicación la presencia de las inscripciones de Valduno (Las Regueras), ${ }^{31}$ Castiello de Doriga (Cornellana, Salas), ${ }^{32}$

\footnotetext{
26 En el ámbito de ese recorrido cabe destacar la inscripción ya mencionada dedicada a Júpiter por los colliacinos y arronidaecos, que se conserva en la sacristía de la iglesia de Serrapio, en el concejo de Aller (CIL II, 2697). Cf. SANTOS 2007.

27 A.E. 1935, n 12. Más detalles en JimÉnEZ - RodríGuez 1991, así como SANTos 2009 b y 2011 a.

28 CID 2000.

29 Más detalles en SANTOS 2009a, 481-509.

30 Álvarez Marrero 1985, 517.

31 CARTES 2000, 199-208.

32 CIL II, 5750. Cf. SAntos 2013a, 79-81.
} 
Santiago de Tuña (Tineo) dedicada a los Lares Viales, ${ }^{33}$ Ablaneda (Salas) ${ }^{34}$ y Naraval (Tineo), ${ }^{35}$ estas dos últimas aparecidas en contextos mineros, o la consagrada igualmente a los Lares Viales de Comba (Allande), ${ }^{36}$ además de la dedicada a estos mismos dioses descubierta en Lucus Asturum. ${ }^{37}$

En síntesis podemos afirmar que la presencia de militares en el territorio que se extiende entre la Cordillera Cantábrica y el mar durante los años de conquista del Norte peninsular no está constatada a ningún nivel, por lo que difícilmente se puede asegurar que destacamentos romanos (legiones y/o unidades auxiliares) ocuparan dicho territorio como consecuencia de los avatares derivados de la anexión de dicho suelo. Más bien el interés romano se centraría básicamente en la línea de montaña, lo que explicaría la concentración de tropas (con sus respectivos campamentos) en este espacio geográfico, como muy bien ha demostrado E. Peralta para el caso del frente cantabro, ${ }^{38}$ aunque en modo alguno se pueda realizar esta misma apreciación en el caso de los astures (muy improbable campamento romano en La Carisa a más de 1700 metros de altitud), que quieren convertir, como hace dicho investigador con respecto a los cántabros, en último baluarte de los astures transmontanos contra Roma.

En última instancia este conjunto de recintos castrenses ejercería una actividad de control, desde lo alto de las montañas, sobre el territorio de los habitantes de la franja costera hasta la cordillera, pero sin necesidad de desplazarse en gran número ni de manera continuada por todo el suelo que se extendía desde la falda de los montes hasta la rasa litoral cantábrica. Tal situación derivaría sin duda del hecho de que, para el Estado romano, la anexión del suelo de la Asturias antigua (ocupado por los astures transmontanos, así como en parte por los cántabros en la zona oriental de la región y por los galaicos en la occidental) no equivalía a ocupación de todo el espacio geográfico habitado por dichas poblaciones sino únicamente al control del mismo. ¿Y eso por qué motivo? En realidad porque a los romanos tampoco les interesaba dicho territorio en su totalidad sino únicamente las áreas estratégicas y las zonas susceptibles de ser aprovechadas desde el punto de vista económico (minería del oro y sector agropecuario). Así pues, en el fondo, lo que el Estado romano perseguía no sería más que clausurar el ciclo que se iniciaba con la conquista del territorio, se continuaba con la organización administrativa del mismo y se cerraba con la explotación de sus recursos económicos más sobresalientes (dicho plan se iría realizando en fases sucesivas, la última de las cuales solo podría desarrollarse tras la conquista y administración del suelo).

La documentación escrita antigua de que disponemos en la actualidad no nos permite concretar la presencia de contingentes de soldados romanos en el suelo de Asturias durante la Antigüedad en el transcurso de los años en que se desarrollaron los acontecimientos militares correspondientes a las guerras astur-cántabras. Tampoco los restos materiales (excesivamente débiles en la mayoría de las ocasiones) vinculados a esta

33 SANTOS 2012a, 179-180.

34 CIL II, 5739. Diego Santos 1985, 78-79 y SAntos 1999.

35 MenÉNDEZ 1950, 287-296.

36 García Linares 1982.

37 Más detalles sobre el trazado de este camino romano y su posterior conversión en infraestructura del Camino de Santiago en SANTos 2011b, 456-464.

38 Peralta 2001, 2002 y 2003. 
participación bélica (y/o a la presencia del ejército romano en tales avatares) resultan ser contemporáneos de los años de conquista del actual territorio asturiano. Por desgracia no podemos constatar en la actualidad que, de la misma manera que sucedería en el caso de Cantabria, existieran enclaves castrenses significativos para facilitar el acceso (y control) hacia el espacio geográfico que se extendía desde el relieve montañoso hasta el mar Cantábrico. Bien es verdad que, en las décadas posteriores, se detecta la presencia de destacamentos militares romanos en el Suroccidente de Asturias; estos contingentes militares (integrados por unidades no muy amplias) parecen estar vinculados con otros existentes en la región de El Bierzo leonés, donde las últimas investigaciones parecen conectar su presencia tal vez ya desde los momentos finales de la fase de anexión de dicho territorio (en cualquier caso creemos que sus objetivos se centrarían inmediatamente en el control y aprovechamientos de los distritos mineros de oro).

Frente a ello los indicios acerca de la presencia romana en la franja litoral cantábrica de Asturias parecen ser más fuertes, en especial en el entorno de Gijón, primero a través de las Aras Sestianas y después a través del previsible interés de Augusto y, sobre todo, de su administración en dicho espacio geográfico de acuerdo con la lápida consagrada en la Campa Torres al primer emperador romano. El primero de dichos monumentos se conecta sin duda con el cierre de la primera fase de anexión del Norte peninsular, en la que participa Augusto, así como con el intento de organizar de inmediato ese territorio, posiblemente a través de la provincia Transduriana: la erección del mismo por parte del legado imperial (gobernador provincial) Lucio Sestio implica el asentamiento y control de dicho territorio por los romanos, contando sin duda con ese apoyo directo a la conquista por parte de la escuadra romana del Cantábrico. Posiblemente este interés romano se halle en la base del intento frustrado de convertir después la polis Noega en la capital administrativa del conventus jurídico de los astures transmontanos, buscando el Estado romano un paralelismo en cuanto a la administración del nuevo territorio conquistado (dos conventus para los galaicos y otros tantos para los astures, en este caso a uno y otro lado de la cordillera cantábrica).

Estas circunstancias nos llevan a pensar que las acciones militares únicamente se llevarían a cabo en la línea de cordillera y en la franja litoral, mientras que el espacio existente entre ambas sería controlado a través de enlaces (vías de comunicación), cuyo trazado se diseñaría en las décadas inmediatas a la finalización de los enfrentamientos bélicos y que cobrarían fuerza especialmente con los sucesores de Augusto (Tiberio y, sobre todo, Claudio). Bien es verdad que Tiberio, continuando la labor urbanística y municipalizadora desplegada por el primer emperador, ${ }^{39}$ completaría la consolidación (y hasta modernización) de algunos centros urbanos significativos, como se puede observar en la capital de los astures; sin embargo, las últimas excavaciones arqueológicas practicadas en el solar asturicense (en especial en el teatro Gullón) nos permiten centrar en tiempos de Claudio muchos de los avances administrativos (conventus jurídicos) y actividades (técnicas y laborales) que hasta la fecha venían adjudicándose a décadas posteriores (los emperadores Flavios).

39 Abascal 2006. 
En este sentido la presencia de estelas funerarias correspondientes a militares (de la legión X Gemina y VI Victrix) en las zonas mineras de El Bierzo y alrededores parecen confirmar el desarrollo de tales tareas vinculadas al mundo laboral de la obtención del oro de forma intensiva, no ya en tiempos de Vespasiano y los miembros de su dinastía, sino un par de décadas antes al menos. Y desde esta misma perspectiva se conectan con el emperador Claudio hechos militares de gran alcance: por un lado la presencia de los indígenas astures en el marco militar romano como unidades de tropas auxiliares de infantería y caballería (cohortes y alas) y, por otro, la contribución de los soldados a las actividades agrícolas y mineras.

En cualquier caso la integración de las comunidades astures en el marco de la organización romana tras finalizar la conquista se llevaría a efecto en dos etapas cronológicas sucesivas: la primera de ellas, una vez acabados los combates (época de Augusto y dinastía julio-claudia), a través de la contribución abundante de personas de dicho origen en las tropas auxiliares romanas y la segunda mediante la participación de dichos elementos en las tareas vinculadas a los aprovechamientos auríferos por parte romana en su suelo (desde mediados del siglo I d.C. hasta finales de la centuria siguiente con mayor intensidad). ${ }^{40}$

Sobre la inclusión de elementos astures en las tropas romanas en tiempos republicanos apenas tenemos noticias, en contraste con los testimonios correspondientes al Alto Imperio, momento en que se haría frecuente, especialmente en tiempos de Augusto y sus sucesores. Esta presencia se realizaría de dos formas distintas: bien como soldados aislados para cubrir bajas entre las tropas romanas asentadas en suelo hispano como ejército de ocupación, ${ }^{41}$ bien como cuerpos militares reclutados entre los astures para su traslado inmediato a las distintas líneas fronterizas del Imperio. En este sentido la participación de astures transmontanos en el ejército romano se llevaría a efecto mediante su enrolamiento en las unidades de tropas auxiliares de caballería e infantería de denominación astur, de lo que poseemos abundantes ejemplos, quizás el más significativo el del signifer Pintayo: $:^{42}$ tras su adiestramiento en el campamento de la legión romana más próxima (la X Gemina, después la VI Victrix) estos cuerpos militares serían desplazados a las líneas fronterizas del Imperio donde se requeriría con mayor premura su presencia (desde Claudio a quienes superaban los años de servicio reglamentarios se les concedía una serie de prerrogativas, como la ciudadanía latina, el matrimonio legal, el derecho de comercio.....). ${ }^{43}$

Por su parte la segunda forma de integración de los astures transmontanos en el mundo romano, cronológicamente posterior a su reclutamiento en el marco del ejército (en número más abundante), lo constituiría su contribución como mano de obra no especializada en las tareas vinculadas a la explotación de los diferentes distritos mineros que los romanos aprovechan en Asturias, en especial los del Suroccidente: se utilizaría así

40 Le Roux 1989. Cf. SAntos 1997.

41 SANTOS 2004-2005 y 2006b, 112-119.

42 En inscripción aparecida en suelo germánico: CIL XIII, $8098=I L S$ 2580. Cf. SANTOs 2010b, 133-134.

43 Perea 2009. A partir de Vespasiano los astures servirán en el ejército estacionado en las proximidades de sus lugares de origen: ver, p. ej., el caso de Lucio Corona Severo, soldado de la legión VII Gemina (CIL II, 5733), en inscripción aparecida en Ujo (Mieres, Asturias). 
durante un período de casi 2 siglos (desde Claudio al parecer) esa mano de obra como fuerza de trabajo más importante en el contexto de los aprovechamientos mineros. ${ }^{44}$ No obstante, el sector minero no sería el único que recibiría un gran impulso como consecuencia de la presencia y actuación romana sino que, y vinculado en este caso al menos en parte a las unidades militares, se potenciaría igualmente el agropecuario a través de las parcelas asignadas y cultivadas por cada una de las unidades de tropas (prioritariamente auxiliares) asentadas en el Norte peninsular (los prata).$^{45}$ De esta manera los indígenas astures no solo ampliarían el espacio cultivable, ${ }^{46}$ sino que se aprovecharían de la introducción de un instrumental laboral mucho más evolucionado, relacionado sin duda con la nueva metalurgia del hierro, que los romanos potenciarían entre las poblaciones del Norte peninsular. ${ }^{47}$

\section{BiBLIOGRAFÍA}

Abascal, J. M. (2006): "Los tres viajes de Augusto a Hispania y su relación con la promoción jurídica de ciudades", Iberia 9, 63-78.

Álvarez Marrero, M. (1985): “Una vía antigua en Asturias”, BIDEA 115, 509-517.

Burgos, E. (2007): "Una revisión del conjunto epigráfico de Ujo (Asturias)", [en] A. Fanjul (coord.), Estudios varios de arqueología castreña, Teverga, 103-118.

CABrero, J. (2011): "La marina militar romana como elemento de disuasión para la conquista", [en] G. Bravo - R. González Salinero (eds), Propaganda y persuasión en el mundo romano, Madrid, 351-364.

Cartes, E. (2000): “Lápida funeraria de Sestio Munigálico”, Nuestro Museo 2, 199-208.

CID, R. (2000): "La lápida a los Lares Viales de Lugo de Llanera (Asturias)“, Nuestro Museo 2, 187-201.

CorTÉs, C. (2013): Epigrafia en los confines de las ciudades romanas, Roma.

Diego SAntos, F. (1985): Epigrafía romana de Asturias, Oviedo.

García LinAREs, A. (1982): “Una lápida a los Lares Viales en Comba (Allande)”, BIDEA 107, 774-783.

González, D. - A. Menéndez - A. Álvarez (2008): “El campamento de Moyapán (Ayande, Asturias)", Férvedes 5, 363-371.

González, E. - Ma C. CARreÑo (1998): “La capital del extremo noroeste hispánico: Lucus Augusti y su tejido urbano”, [en] Los orígenes de la ciudad en el noroeste hispánico, Lugo, 1171-1208.

GonzÁlez, J. M. (1956): "Mansiones del trayecto de vía romana Lucus Asturum-Lucus Augusti”, Archivum 6, 287-302.

GonzÁlez EchegaraY, J. - J. M. Solana (1975): “La legión IV Macedónica en España”, HAnt $5,151-203$.

\footnotetext{
44 Más detalles en SANTOS 2011b, 311-362, especialmente 334-346.

45 CORTÉS 2013, 239-244.

46 Mocsy 1972; VitTinghoff 1974.

47 Ver, como ejemplo, SANTOS 2010a.
} 
JiMÉNEZ, A. - J. RodRíGUEZ (1991): “La lápida de Gayo Sulpicio Úrsulo: ¿una falsificación de época?", HAnt 15, 83-90.

Le Roux, P. (1989): “Exploitations minières et armées romaines: essai d'interprétation”, [en] Minería y metalurgia en las antiguas civilizaciones mediterráneas, Madrid, 171-182.

MANGAS, J. (1996): "El trabajo en las minas de la Hispania romana", [en] El trabajo a través de la historia, Madrid, 45-59.

Mangas, J. - D. Martino (1997): “Princeps Cantabrorum en una nueva inscripción”, Gerión 15, 321-339.

MARTINO, E.

(1987): Los nombres de la conquista, I: Los nombres históricos, León.

(1989): Los nombres de la conquista, II: Los nombres militares, Santander.

Maya, J. L. - F. Cuesta (2001): El castro de la Campa Torres, Gijón.

MenÉndez, M. (1950): “Árula de Naraval”, Revista de Letras de la Universidad de Oviedo 3, 287-296.

Mocsy, A. (1972): "Das Problem der militärische territorium im Donauraum", AAntHung 20, 133-168.

Pastor, M. (1977): “En torno a la ubicación del mons Vindius”, Durius 9-10, 147-155.

Peralta, E.

(2001): "Los castra aestiva del bellum cantabricum: novedades arqueológicas", [en] I Congreso Internacional de Historia Antigua, Valladolid, 173-182.

(2002): "Castros y campamentos de campaña de las guerras cántabras", [en] Los poblados fortificados del Noroeste de la Península Ibérica, Navia, 225-240.

(2003): "Los campamentos de las guerras cántabras de Iguña, Toranzo y Buelna (Cantabria)", Arqueología militar romana en Hispania, Madrid, 327-338.

(2004): "Cuestiones histórico-arqueológicas sobre el Bellum Cantabricum y el desembarco romano en la costa cántabra", Sautuola 10, 85-130.

Perea, S. (2009): "Los diplomas militares: documentos singulares para la integración jurídica y social de los soldados peregrini al servicio de Roma", [en] G. Bravo - R. González Salinero (eds.), Formas de integración en el mundo romano, Madrid, 97-118.

SANTOS, N.

(1982): "La conquista romana del N.O. de la Península Ibérica”, Latomus 41, 5-49.

(1988): El ejército y la romanización de Galicia, Oviedo.

(1996): “Gigia, la ciudad romana de Gijón”, MHA 17, 215-237.

(1997): "Ejército romano y minería del oro en el Norte de la Península Ibérica", HAnt 21, 109-122.

(1999): “Lápida funeraria de Flavius Cabarcus", Nuestro Museo 1, 125-130.

(2002): "La inscripción de Nicer hallada en la Corredoira (Vegadeo) y los albiones (galaicos) del Occidente de Asturias", [en] J. M. Gómez Tabanera (ed.), En torno al bimilenario del Eo, Oviedo, 279-298.

(2004-2005): "El final de las guerras astur-cántabras y la desmilitarización del ejércxito romano en territorio de los astures", ETF (Historia Antigua) 17, 237-250.

(2006a): Ejército romano, administración y vida civil en territorio de los astures, Astorga. (2006b): "La consolidación del ejército romano de ocupación en territorio de los astures (años 20-68)", Sautuola 22, 112-119.

(2007): "El culto a Júpiter en la Asturias romana: sincretismo y arraigo", [en] L. Hernández 
(coord.), El mundo religioso hispano bajo el Imperio Romano: pervivencias y cambios, Valladolid.

(2009a): Asturias, los astures y la administración romana durante el Alto Imperio, Oviedo. (2009b): "Gayo Sulpicio Úrsulo, primer comandante astur de una legión romana", Aquila legionis 12, 41-57.

(2010a): "Hito terminal de los prados militares entre la cohorte IIII de los galos y la civitas de los luggones", Astorica 29, 41-65.

(2010b): Militares astures en el ejército romano, Madrid (monográfico Aquila legionis 13). (2011a): "A vueltas con la inscripción de Gayo Sulpicio Úrsulo aparecida en Ujo (Mieres, Asturias) y su posible falsificación", [en] J. Martínez (ed.), Falsificadores y falsarios de la Literatura Clásica, Madrid, 245-258.

(2011b): Asturias, los astures y la minería romana del oro, Oviedo.

(2012a): "El culto a los Lares Viales en Asturias", Ilu. Revista de Ciencias de las Religiones $17,173-184$.

(2013a): Costumbres funerarias y vida de ultratumba en la Asturias antigua, MadridSalamanca.

(2013b): “Ara a Júpiter hallada en Serrapio, concejo de Aller (Asturias)”, [en] Homenaje al Prof. García Teijeiro, Valladolid, 951-959.

(2014a): "Los astures transmontanos y la presencia de Roma", Conquistadores y conquistados: relaciones de dominio en el mundo romano, [en] G. Bravo - R. González Salinero (eds), Madrid, 201-215.

(2014b): "Elites locales en la Asturias romana: principes y magistratus", [en] Homenaje al Prof. Rodríguez Neila, Córdoba (en prensa).

(2014c):"El mons Vindius, la divinidad Vindonius y las guerras astur-cántabras en la Cordillera Cantábrica" (en prensa).

Vittinghoff, F. (1974): "Das Problem des Militärterritoriums in den vorseverischen Kaiserzeit", [en] I diritti locali nelle province romane con particolare risguardo alle condizioni giuridiche del suolo, Roma, 109-124. 